$\begin{array}{ll}\text { PublisherName } & : \text { BioMed Central } \\ \text { PublisherLocation } & : \text { London } \\ \text { Publisherl mprintName } & \text { : BioMed Central }\end{array}$

Luiz Antônio Barreto de Castro

Dario Grattapaglia

\title{
Gait analysis assisted by robotic walker in patients with post-stroke hemiparesis
}

Articlel nfo

\begin{tabular}{|c|c|}
\hline ArticlelD & 3012 \\
\hline ArticleDOI & 10.1186/1753-6561-8-S4-P267 \\
\hline ArticleCitationID & P267 \\
\hline ArticleSequenceNumber & 317 \\
\hline ArticleCategory & Poster presentation \\
\hline ArticleFirstPage & 1 \\
\hline ArticleLastPage & 2 \\
\hline \multirow[t]{2}{*}{ ArticleHistory } & RegistrationDate : 2014-10-1 \\
\hline & : 2014-10-1 \\
\hline
\end{tabular}

ArticleCopyright $\quad$ : Loterio and Bastos-Filho; licensee BioMed Central Ltd.2014

This article is published under license to BioMed Central Ltd. This is an Open Access article distributed under the terms of the Creative Commons Attribution License ( $\mathrm{http}: / /$ creativecommons.org/licenses/by/4.0), which permits unrestricted use, distribution, and reproduction in any medium, provided the original work is properly cited. The Creative Commons Public Domain Dedication waiver (http://creativecommons.org/publicdomain/zero/1.0/) applies to the data made available in this article, unless otherwise stated.

ArticleGrants

ArticleContext

: 1291988S4S4 
Flávia Loterio, Aff1

Corresponding Affiliation: Aff1

Teodiano Bastos-Filho, Aff1

\section{Aff1 Universidade Federal do Espírito Santo, Vitória, ES, Brazil}

Stroke is the leading cause of motor dysfunction in adults worldwide. The motor impairment, characteristic of a post-stroke patient, is the hemiparetic gait. This paper proposes a gait analysis assisted by a robotic walker in patients with post-stroke hemiparesis. The test group will have two categories: the first consisting of healthy subjects, and the second one by subjects with post-stroke hemiparesis. Both groups will perform an initial trajectory without the aid of a walker, and another one with its assistance. This route is a straight line, in a flat ground. After training with the walker, volunteers participating repeat the trajectory using the device. The robotic walker is equipped with 3D force sensors in the forearm support, which can confirm the correct weight applied to it. It also can deduce the subject's movement intentions, through the efforts made by his/her upper limbs. Spatio-temporal parameters of gait using inertial sensors will be analyzed. These sensors will be placed in specific points of the subject's legs, and a laser scanning sensor will be located in the center of the walker in order to get distances to the legs. Electromyography (EMG) electrodes will be also placed on the subject's legs to evaluate the muscle activity and energy consumption during the gaits. After analyzing the data, the results will be compared between the two groups and between the gaits before and after the training. The results might be useful for the process of rehabilitation of post-stroke patients, and in normal and hemiparetic gait.

This PDF file was created after Publication. 